\title{
Publisher Correction: Neuromodulation in circuits of aversive emotional learning
}

\section{Ekaterina Likhtik (1) and Joshua P. Johansen (1)}

Correction to: Nature Neuroscience https://doi.org/10.1038/s41593-019-0503-3, published online 24 September 2019.

In the version of this article initially published online, arrows in Fig. $6 \mathrm{~b}$ were incorrect; LA/B was sometimes incorrectly abbreviated as BLA; and the Acknowledgements (indicating financial support) and Competing Interests sections were omitted. The authors received funding from the Japan Society for the Promotion of Science (KAKENHI, 19H05234 to J.P.J.) and the National Institute of Mental Health (R21MH114182 to E.L.). These errors have been corrected in the PDF and HTML versions of this article.

a

\begin{tabular}{|c|c|c|}
\hline & D1,5-R & D2,3-4-R \\
\hline & $\begin{array}{l}\text { Metabotropic } \\
\text { (Gs-coupled) }\end{array}$ & $\begin{array}{l}\text { Metabotropic } \\
\text { (Gi-coupled) }\end{array}$ \\
\hline HPC & $\begin{array}{l}\text { - Facilitates context fear conditioning } \\
\text { - Facilitates LTP }\end{array}$ & \\
\hline LA/B & $\begin{array}{l}\text { - Reduces feedforward inhibition and enhances LTP } \\
\text { - Increases excitability of GABAergic cells } \\
\text { - Enhances fear conditioning }\end{array}$ & $\begin{array}{l}\text { - Facilities fear conditioning } \\
\text { - Facilities extinction } \\
\text { - Reduces feedforward inhibition and enhances LTP }\end{array}$ \\
\hline mPFC & $\begin{array}{l}\text { - Facilitates fear learning } \\
\text { - Facilitates extinction } \\
\text { - Enhances pyramidal cell excitability and LTP }\end{array}$ & $\begin{array}{l}\text { - Facilitates extinction } \\
\text { - Reduces feedforward inhibition }\end{array}$ \\
\hline
\end{tabular}

a

\begin{tabular}{|c|c|c|}
\hline & D1,5-R & D2,3-4-R \\
\hline & $\begin{array}{l}\text { Metabotropic } \\
\text { (Gs-coupled) }\end{array}$ & $\begin{array}{l}\text { Metabotropic } \\
\text { (Gi-coupled) }\end{array}$ \\
\hline HPC & $\begin{array}{l}\text { - Facilitates context fear conditioning } \\
\text { - Facilitates LTP }\end{array}$ & \\
\hline LA/B & $\begin{array}{l}\text { - Reduces feedforward inhibition and enhances LTP } \\
\text { - Increases excitability of GABAergic cells } \\
\text { - Enhances fear conditioning }\end{array}$ & $\begin{array}{l}\text { - Facilities fear conditioning } \\
\text { - Facilities extinction } \\
\text { - Reduces feedforward inhibition and enhances LTP } \\
\text { - Enhances GABAergic inhibition }\end{array}$ \\
\hline mPFC & $\begin{array}{l}\text { - Facilitates fear learning } \\
\text { - Facilitates extinction } \\
\text { - Enhances pyramidal cell excitability and LTP }\end{array}$ & $\begin{array}{l}\text { - Facilitates extinction } \\
\text { - Reduces feedforward inhibition }\end{array}$ \\
\hline
\end{tabular}

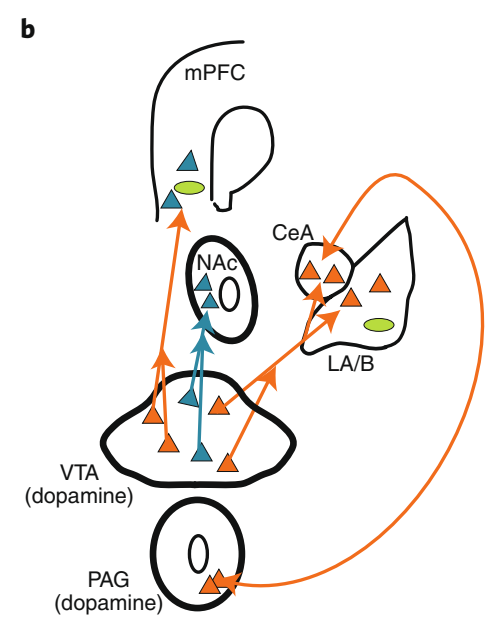

b

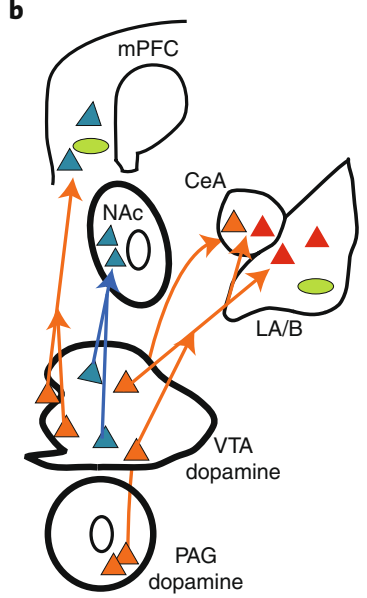

Fig. 6 | Original and Corrected.

Published online: 11 October 2019

https://doi.org/10.1038/s41593-019-0529-6 